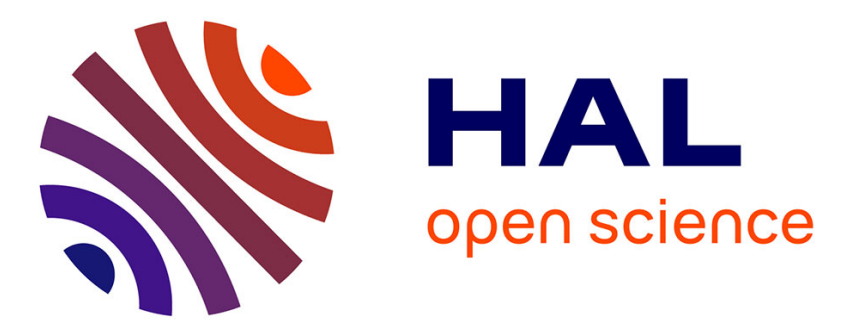

\title{
Adherence of French cardiologists to guidelines for non-cardiac surgery
}

Rémi Schweizer, Gilles Godet, Pierre-Yves Petit, Jennifer Elia, Pauline Guette, Gérard Finet, Jean-Luc Fellahi, Vincent Piriou

\section{To cite this version:}

Rémi Schweizer, Gilles Godet, Pierre-Yves Petit, Jennifer Elia, Pauline Guette, et al.. Adherence of French cardiologists to guidelines for non-cardiac surgery. Anaesthesia Critical Care \& Pain Medicine, 2016, In press. 10.1016/j.accpm.2015.12.009 . hal-01301147

\section{HAL Id: hal-01301147 https://hal-univ-rennes1.archives-ouvertes.fr/hal-01301147}

Submitted on 10 May 2016

HAL is a multi-disciplinary open access archive for the deposit and dissemination of scientific research documents, whether they are published or not. The documents may come from teaching and research institutions in France or abroad, or from public or private research centers.
L'archive ouverte pluridisciplinaire HAL, est destinée au dépôt et à la diffusion de documents scientifiques de niveau recherche, publiés ou non, émanant des établissements d'enseignement et de recherche français ou étrangers, des laboratoires publics ou privés. 


\section{Adherence of French cardiologists to}

\section{guidelines of non-cardiac surgery}

Remi SCHWEIZER ${ }^{A^{*}}$, M.D., Gilles GODET ${ }^{B}$, M.D., Pierre-Yves PETIT ${ }^{C}$, M.D., Jennifer ELIA ${ }^{A}$, M.D., Pauline GUETTE ${ }^{B}$, Gerard FINET ${ }^{D}$, M.D., Ph.D., Jean-Luc FELLAHI ${ }^{A}$, M.D., Ph.D., Vincent PIRIOU ${ }^{C}$, M.D., Ph.D.

A Department of Anaesthesiology and Intensive Care, Louis Pradel Hospital, Hospices Civils de Lyon, 28 avenue du Doyen Lepine, 69677 Bron, France

${ }^{B}$ Department of Anaesthesiology and Intensive Care II, Pontchaillou University Hospital, 2 rue Henri Le Guilloux, 35000 Rennes, France

${ }^{\mathrm{C}}$ Department of Anaesthesiology and Intensive Care, Lyon Sud Hospital, Hospices Civils de Lyon, 165 Chemin du Grand Revoyet, 69495 Pierre Benite, France

${ }^{D}$ Interventional Cardiology Department, Louis Pradel Hospital, Hospices Civils de Lyon, 28 avenue du Doyen Lepine, 69677 Bron, France

\section{Corresponding Author:}

Remi SCHWEIZER

Address: Department of Anaesthesiology and Intensive Care, Louis Pradel Hospital, Hospices Civils de Lyon, 28 avenue du Doyen Lepine, 69677 Bron, France

Phone: +33665716877

Email: remi.schweizer@gmail.com 


\title{
Adherence of French cardiologists to guidelines for non-cardiac surgery
}

Rémi SCHWEIZER ${ }^{A^{*}}$, M.D., Gilles GODET ${ }^{B}$, M.D., Pierre-Yves PETIT ${ }^{C}$, M.D., Jennifer ELIA ${ }^{A}$, M.D., Pauline GUETTE ${ }^{B}$, Gerard FINET ${ }^{D}$, M.D., Ph.D., Jean-Luc FELLAHI ${ }^{A}$, M.D., Ph.D., Vincent PIRIOU ${ }^{C}$, M.D., Ph.D.

A Department of Anaesthesiology and Intensive Care, Louis Pradel Hospital, Hospices Civils de Lyon, 28 avenue du Doyen Lepine, 69677 Bron, France

${ }^{B}$ Department of Anaesthesiology and Intensive Care II, Pontchaillou University Hospital, 2 rue Henri Le Guilloux, 35000 Rennes, France

${ }^{\mathrm{C}}$ Department of Anaesthesiology and Intensive Care, Lyon Sud Hospital, Hospices Civils de Lyon, 165 Chemin du Grand Revoyet, 69495 Pierre Benite, France

${ }^{D}$ Interventional Cardiology Department, Louis Pradel Hospital, Hospices Civils de Lyon, 28 avenue du Doyen Lepine, 69677 Bron, France

Corresponding Author:

Rémi SCHWEIZER

Phone: +33665716877

Email: remi.schweizer@gmail.com

Keywords: Non-cardiac surgery, preoperative evaluation, coronary artery disease, guideline adherence

\begin{abstract}
Introduction: In order to evaluate whether cardiologists follow guidelines, we studied patients who were seen for a pre-operative cardiologic consultation prior to surgery.
\end{abstract}

Methods: This retrospective study took place in two surgical units (Vascular and Orthopaedic) in two different university hospitals in 2013. The patient eligibility criteria were: planned elective surgery, cardiologic consultation prior to anaesthesiology consultation and lack of any unstable cardiac condition. The primary endpoint was determination of appropriate use of preoperative cardiac stress exams (CSE).

Results: The study included 238 patients who were seen by 131 different cardiologists. Of 238 patients, 60 had a CSE before surgery, but only 7/60 (12\%) were deemed to be necessary.

Seven out 15 (47\%) patients with an indication for a CSE actually underwent said exam. Sixty- 
six \% of patients $(156 / 238)$ had a resting trans-thoracic echocardiography before surgery, while only $27 / 156(17 \%)$ were considered of appropriate use.

Among patients with known coronary arterial disease, 59/73 (81\%) received a statin, 60/73 $(82 \%)$ received an antiplatelet agent, and 38/73 (52\%) received a beta-blocker. Among patients with planned arterial surgery, 86/137 (63\%) received a statin and 100/137 (73 \%) patients received an antiplatelet agent.

Of the 159 consultation reports that were examined, only 5 (3\%) mentioned the Lee score and 117 (74\%) were concluded with "no contraindication" or a similar phrase.

Discussion: In this study, we found that guidelines were generally not used when cardiologists evaluated patients for non-cardiac surgery. This is evidenced by the number of inappropriate exams performed, the lack of true perioperative risk stratification, and incomplete optimization of long-term treatment regimens.

\section{Introduction}

A standardised evaluation of perioperative cardio-vascular risk would identify those patients with the highest likelihood of cardiac complications. Such a strategy would allow patients to benefit from appropriate diagnostic and therapeutic modalities with the goal of reducing perioperative cardio-vascular morbidity and mortality, without performing unnecessary exams. These strategies are available and regularly updated in international guidelines [1-4]. French guidelines, better adapted to the French medical system, have been jointly written by the French Cardiology and French Anaesthesiology Societies in 2011 [5]. However, adherence of perioperative physicians (including anaesthesiologists) to these guidelines seems poor. This is especially demonstrated by examining the appropriateness of exams ordered for the detection and quantification of coronary arterial disease [6-11].

While often requested in the preoperative period for the evaluation of perioperative cardio-vascular risk, only one study tried to evaluate cardiologist adherence to these guidelines. Based on the North-American guidelines published in 2007, a survey was published on how NorthAmerican interventional cardiologists managed patients with coronary stents undergoing noncardiac surgery $[4,12]$. The results were in line with guidelines concerning the type of coronary stent to use and the optimal delay before proceeding with non-cardiac surgery. On the other hand, the use of cardiac stress exams (CSE) and the perioperative management of platelet aggregation inhibiting drugs were less appropriate. However, interpretation of the latter results may be biased because of low participation (only $10 \%$ of cardiologists answered the survey).

In order to study French cardiologist adherence to current guidelines, especially the appropriate use of CSE, independently of the influence of anaesthesiologists, we decided to study a group of patients seen by a cardiologist for elective surgery prior to the anaesthesiology consultation.

\section{Patients and Methods}


This was a retrospective study involving a cohort of French cardiologists who performed consultations for patients with planned elective, non-cardiac surgery. All patients were seen by a cardiologist prior to their consultation with an anaesthesiologist. On most occasions, the surgeon ordered the cardiologic consultation.

No ethics committee was contacted.

Patients were sampled from two different French university hospitals: the Vascular Surgery Unit at the Pontchaillou Hospital, Rennes, from January to December 2013 and the Orthopaedic Surgery Unit at the Lyon Sud Hospital, Pierre Benite, Hospices Civils de Lyon, from August to October 2013.

All patients with planned elective surgery who had a cardiologic consultation before an anaesthesiology consultation were included in this study. Patients were excluded if they had an unstable cardiac condition (defined as: unstable angina pectoris, acute heart failure, significant cardiac arrhythmias, symptomatic valvular heart disease, or myocardial infarction within the past 30 days $^{5}$ ). The primary endpoint was the appropriateness of the CSE ordered by the cardiologist and whether or not such exams were consistent with French guidelines [5].

A CSE was considered of appropriate use if: 1 ) delaying surgery was possible, 2) the result would change therapeutic strategies, 3) the functional capacity of the patient was less than 4 metabolic equivalents of task (METs), and 4) the Revised Cardiac Index Risk (RCRI) score was 2 or more in the setting of a high risk surgery (such as abdominal aortic surgeries or distal arterial bypass) or 3 or more in the setting of an intermediate risk surgery [5].

Secondary endpoints were 1) the appropriateness of the resting trans-thoracic echocardiography (TTE) ordered by cardiologists as defined in both North-American and French guidelines, 2) the adequacy of chronic medication regimens, 3) the perioperative cardiac risk evaluation defined by the cardiologist, and 4) the clinically relevant implications of the cardiologic consultation on perioperative management $[5,13]$.

The majority of the data were collected from the anaesthesiology consultation report (RCRI score, clinical evaluation of functional capacity, surgical risk, medication lists, CSE, and TTE testing). The only data extracted from the cardiologic consultation report are the two last secondary endpoints.

The results compiled were completely descriptive in nature. As such, no statistical analysis was necessary; only patient age is shown, expressed by the mean and the standard deviation. All percentages were rounded to the nearest unit.

Patient and cardiologist data were anonymous.

\section{Results}

During the study period, 238 patients were included, seen by 131 different cardiologists: 137 vascular surgery patients and 101 orthopaedic surgery patients. A flow chart diagram for inclusions and associated patient characteristics and planned surgeries are summarized in Figure 1 and Table 1, respectively. 
Cardiologic consultation reports were immediately available for $159 / 238$ patients (67\%). Anaesthesiology consultation reports were available for all patients and contained all data of interest. Table 2 shows the criteria used to evaluate the appropriateness of CSEs.

Sixty CSEs were ordered by cardiologists. Figure 2 shows the type of first-line CSE ordered by cardiologists. Among exercise electrocardiograms, 21/32 (65\%) were not interpretable (no change in clinical or electrical status and the maximal cardiac rate obtained was less than $220-$ age).

Figure 3 shows the appropriateness of the cardiac stress exams ordered by cardiologists. Seven of the 60 (12\%) CSEs ordered by cardiologists were actually indicated as previously defined. Seven out of the 15 (47\%) patients with an indication for a CSE before surgery actually had one performed. Among exercise electrocardiograms, 65\% were not interpretable (no change in clinical or electrical status and the maximal cardiac rate obtained was less than 220-age).

Sixty-six \% (156/238) of patients had a resting TTE ordered by a cardiologist before surgery. Among them, $27 / 156$ (17\%) were of appropriate use, 1/156 (<1\%) was of uncertain appropriate use and $128 / 156$ (82\%) were of inappropriate use as defined by French and North-American guidelines [5,13].

Among patients with known coronary artery disease, 59/73 (81\%) had a statin, 60/73 (82\%) had an antiplatelet agent and 38/73 (52\%) had beta-blockers ordered as long-term treatments. Among patients with planned arterial surgery, $86 / 137$ (63\%) received a statin and 100/137 (73\%) patients had an antiplatelet agent ordered as long-term treatments.

No patients had coronary revascularisation or implantations of pacemakers / cardioverterdefibrillators before surgery in this cohort.

Among patients with available cardiologic consultation reports, 5/159 (3\%) had the RCRI score (or Lee Score) explicitly mentioned. Seventy-four \% (117/159) of cardiologic consultation reports were concluded by "no contraindication," "clear for surgery," "authorization to anaesthetize," or a similar phrase.

\section{Discussion}

This is the first retrospective study conducted to analyse the adherence of perioperative guidelines for cardiac patients undergoing non-cardiac surgery. In this study, our results indicate that there is generally poor adherence to such guidelines. Although the recommendations present in the relevant guidelines have been well established for many years, they were usually not followed in the preoperative cardiovascular evaluation. There was a lack of perioperative cardiovascular risk stratification and inappropriate use of complementary exams. We also noted the lack of well-tested chronic therapies such as antiplatelet agents and/or statins used in both vascular surgery patients and coronary artery disease patients. 
The majority of CSEs were primarily performed by exercise ECGs. It was easy to predict that those exams would be non-interpretable when patients were scheduled for arthroplasty or vascular surgery of the lower limbs because of disability.

It's important to also note that the conclusions from cardiologists such as "no contraindication to anaesthesia" are not helpful for patient management, as they provide no direction for perioperative monitoring or therapeutic management. In case of a major adverse cardiac event, such a conclusion may only partly cover for the anaesthesiologist.

The cost of inappropriate exams can be estimated using Table 3 in the supplementary appendix.

This study has certain limitations. First, since it is a retrospective analysis, there are some inherent biases with this type of study. We did not perform an a priori power analysis and arbitrarily determined the number of patients to include. Consequently, even if results seem impressive, appropriate caution should be used when making interpretations.

We decided to omit the introduction of preoperative Beta-Blockers in high risk surgeries which can have potentially harmful effects if the introduction is not carefully performed $[1,2,5]$. Unfortunately, precise data were not fully available for all patients.

We also found that the anaesthesiologists did not systematically assess functional capacity in a standardised manner. This may have led to a few misclassifications of the primary endpoint. To limit this type of bias, the last North-American guidelines explicitly recommend using a standardised questionnaire: the DASI questionnaire (Duke Activity Status Index) $[1,14,15]$.

In addition, some of our results refer to patients with available cardiologic consultation reports; indeed, only $67 \%$ of the patients had this report available. However, the missing reports did not affect most of the endpoints.

The inappropriate ordering of a CSE may be attributed to differences between the guidelines used. For example, under the "stable ischaemic heart disease" guidelines, a stress test may be indicated for a patient who would not otherwise obtain one if the "perioperative" guidelines are used. The 2013 North-American guidelines about appropriate use criteria for the detection and risk assessment of stable ischaemic heart disease clarify the question [16].

The inappropriate use of a resting TTE may be due to inadequacy between European and North-American or French guidelines: the last European guidelines made a weak recommendation in favour of left ventricular ejection fraction evaluation in the pre-operative period in case of highrisk surgery, even if the patient is not suspected of having any heart disease (Class Ilb, level of evidence C) $[1-5,13]$. This is because preoperative left ventricular ejection fraction has been identified as a prognostic factor of perioperative morbidity and mortality. In the French and NorthAmerican guidelines, it is not recommended. A recent study even suggests a worse outcome in patients when they had a resting TTE before major elective non-cardiac surgery [17].

In order to improve this system, we suggest that cardiologic consultations be requested by the anaesthesiologist with specific questions and with data readily available. This may lead to fewer unnecessary exams and more useful conclusions. However, it would imply a better adherence of the French anaesthesiologists themselves to guidelines for non-cardiac surgery [8]. We also think that with strict adherence to these guidelines on both parts, the number of 
preoperative cardiac exams would dramatically decrease and postponing surgery would be exceptional.

This study excluded patients with any unstable cardiac condition. In case of an unstable cardiac condition, the cardiologist will of course play a major role.

\section{Conclusions}

In this study, we found that the adherence of cardiologists to non-cardiac surgery guidelines was generally poor, with many inappropriate cardiologic exams performed, a lack of perioperative risk stratification, and often "empty" conclusions. Obviously, a preoperative cardiologic consultation should never exempt an anaesthesiologist from thoroughly thinking about the cardio-vascular perioperative management, and in France, the final decision of anaesthesia and the modality of this anaesthesia is the responsibility of the anaesthesiologist [18]. However, dissemination of the relevant clinical practice guidelines remains a critical issue for both the anaesthesiology and cardiology communities. 


\section{References}

1. Fleisher LA, Fleischmann KE, Auerbach AD, Barnason SA, Beckman JA, Bozkurt B, et al. 2014 ACC/AHA Guideline on Perioperative Cardiovascular Evaluation and Management of Patients Undergoing Non-cardiac Surgery: A Report of the American College of Cardiology/American Heart Association Task Force on Practice Guidelines. Circulation. 2014;130:2215-45

2. Kristensen SD, Knuuti J, Saraste A, Anker S, Bøtker HE, De Hert S, et al. 2014 ESC/ESA Guidelines on non-cardiac surgery: cardiovascular assessment and management: The Joint Task Force on non-cardiac surgery: cardiovascular assessment and management of the European Society of Cardiology (ESC) and the European Society of Anaesthesiology (ESA). Eur Heart J. 2014;35:2383-431

3. Poldermans D, Bax JJ, Boersma E, Hert SD, Eeckhout E, Fowkes G, et al. Guidelines for pre-operative cardiac risk assessment and perioperative cardiac management in noncardiac surgery The Task Force for Preoperative Cardiac Risk Assessment and Perioperative Cardiac Management in Non-cardiac Surgery of the European Society of Cardiology (ESC) and endorsed by the European Society of Anaesthesiology (ESA). Eur J Anaesthesiol. 2010;27:92-137

4. Fleisher LA, Beckman JA, Brown KA, Calkins H, Chaikof EL, Fleischmann KE, et al. ACC/AHA 2007 Guidelines on Perioperative Cardiovascular Evaluation and Care for Non-cardiac Surgery: A Report of the American College of Cardiology/American Heart Association Task Force on Practice Guidelines (Writing Committee to Revise the 2002 Guidelines on Perioperative Cardiovascular Evaluation for Non-cardiac Surgery). J Am Coll Cardiol. 2007;50:e159-241

5. Société française d'anesthésie et de réanimation (Sfar), Société française de cardiologie (SFC). Prise en charge du coronarien qui doit être opéré en chirurgie noncardiaque. Ann Fr Anesth Reanim. 2011;30:e5-29.

6. Van Gelder FE, de Graaff JC, van Wolfswinkel L, van Klei WA. Preoperative testing in noncardiac surgery patients: a survey amongst European anaesthesiologists. Eur J Anaesthesiol. 2012;29:465-70

7. Vigoda MM, Behrens V, Miljkovic N, Arheart KL, Lubarsky DA, Dutton RP. Perioperative cardiac evaluation of simulated patients by practicing anesthesiologists is not consistent with 2007 ACC/AHA guidelines. J Clin Anesth. 2012;24:446-55

8. Sens N, Payan A, Sztark F, Piriou V. Évaluation du Risque CARDiaque de l'Opéré (RICARDO) : enquête nationale auprès des anesthésistes-réanimateurs concernant 
la prise en charge périopératoire du patient à risque cardiaque. Ann Fr Anesth Reanim. 2013;32:676-83

9. Ellis JE, Tung A, Lee $H$, Lee $H$, Kasza K. Anesthesiologists' preferences for preoperative cardiac evaluation before vascular surgery: results of a mail survey. J Clin Anesth. 2010;22:402-9

10. Vigoda MM, Sweitzer B, Miljkovic N, Arheart KL, Messinger S, Candiotti K, et al. 2007 American College of Cardiology/American Heart Association (ACC/AHA) Guidelines on perioperative cardiac evaluation are usually incorrectly applied by anesthesiology residents evaluating simulated patients. Anesth Analg. 2011;112:940-9

11. Madi-Jebara S, Chalhoub V, Jabbour K, Yazigi A, Haddad F, Richa F, et al. Audit on preoperative cardiac evaluation before non-cardiac surgery: the importance of a pocket guide to improve the anaesthesist's adhesion to ACC/AHA guidelines. Ann $\mathrm{Fr}$ Anesth Reanim. 2009;28:850-4 `

12. Khair T, Garcia B, Banerjee S, Brilakis ES. Contemporary approaches to perioperative management of coronary stents and to preoperative coronary revascularization: a survey of 374 interventional cardiologists. Cardiovasc Revasc Med. 2011;12:99-104

13. American College of Cardiology Foundation Appropriate Use Criteria Task Force, American Society of Echocardiography, American Heart Association, American Society of Nuclear Cardiology, Heart Failure Society of America, Heart Rhythm Society, et al. ACCF/ASE/AHA/ASNC/HFSA/HRS/SCAI/SCCM/SCCT/SCMR 2011 Appropriate Use Criteria for Echocardiography. A Report of the American College of Cardiology Foundation Appropriate Use Criteria Task Force, American Society of Echocardiography, American Heart Association, American Society of Nuclear Cardiology, Heart Failure Society of America, Heart Rhythm Society, Society for Cardiovascular Angiography and Interventions, Society of Critical Care Medicine, Society of Cardiovascular Computed Tomography, Society for Cardiovascular Magnetic Resonance American College of Chest Physicians. J Am Coll Cardiol. 2011;57:1126-66

14. Hlatky MA, Boineau RE, Higginbotham MB, Lee KL, Mark DB, Califf RM, et al. A brief self-administered questionnaire to determine functional capacity (the Duke Activity Status Index). Am J Cardiol. 1989;64:651-4

15. Melon CC, Eshtiaghi P, Luksun WJ, Wijeysundera DN. Validated questionnaire vs physicians' judgment to estimate preoperative exercise capacity. JAMA Intern Med. 2014;174:1507-8.

16. Wolk MJ, Bailey SR, Doherty JU, Douglas PS, Hendel RC, Kramer CM, et al. ACCF/AHA/ASE/ASNC/HFSA/HRS/SCAI/SCCT/SCMR/STS 2013 multimodality appropriate use criteria for the detection and risk assessment of stable ischemic 
heart disease: a report of the American College of Cardiology Foundation Appropriate Use Criteria Task Force, American Heart Association, American Society of Echocardiography, American Society of Nuclear Cardiology, Heart Failure Society of America, Heart Rhythm Society, Society for Cardiovascular Angiography and Interventions, Society of Cardiovascular Computed Tomography, Society for Cardiovascular Magnetic Resonance, and Society of Thoracic Surgeons. J Am Coll Cardiol. 2014 Feb 4;63(4):380-406

17. Wijeysundera DN, Beattie WS, Karkouti K, Neuman MD, Austin PC, Laupacis A. Association of echocardiography before major elective non-cardiac surgery with postoperative survival and length of hospital stay: population based cohort study. BMJ. 2011 Jun 30;342:d3695

18. Conseil National de l'Ordre des Médecins. Recommandations concernant les relations entre anesthésistes-réanimateurs et chirurgiens, autres spécialistes ou professionnels de santé. http://www.conseil-

national.medecin.fr/sites/default/files/anesth.pdf, updated on January 2015 Caisse Primaire d'Assurance Maladie, Cotation Commune des Actes Médicaux. http://www.ameli.fr/fileadmin/user_upload/documents/CCAM_V39.10.pdf, updated on January 2015 
Table 1: Characteristics of included patients and planned surgeries

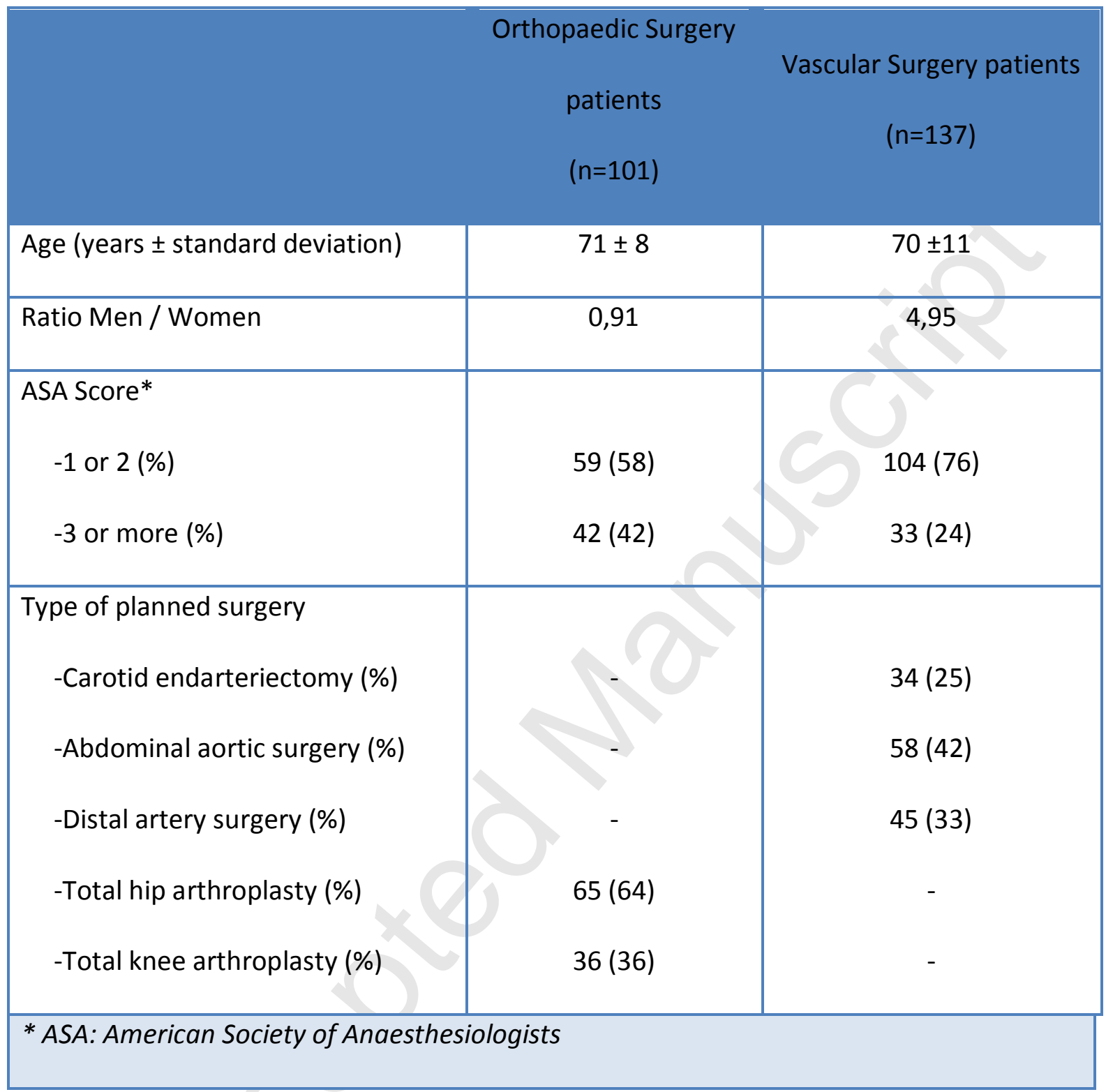


Table 2: Criteria to evaluate the appropriateness of non-invasive cardiac stress exams

\begin{tabular}{|c|c|}
\hline & $\begin{array}{l}\text { Total cohort } \\
(n=238)\end{array}$ \\
\hline \multicolumn{2}{|l|}{ Surgical risk ${ }^{\mathrm{a}}$} \\
\hline Low (\%) & $0(0)$ \\
\hline Intermediate (\%) & $181(76)$ \\
\hline High (\%) & $57(24)$ \\
\hline \multicolumn{2}{|l|}{ Clinical evaluation of functional capacity ${ }^{b}$} \\
\hline$<4 \mathrm{METs}^{\mathrm{b}}(\%)$ & $88(37)$ \\
\hline$\geq 4 \mathrm{METs}^{\mathrm{b}}(\%)$ & $150(63)$ \\
\hline \multicolumn{2}{|l|}{ Revised Cardiac Index Risk score ${ }^{b}$} \\
\hline 1 or $0(\%)$ & $181(76)$ \\
\hline $2(\%)$ & 40 (17) \\
\hline 3 or more $(\%)$ & $17(7)$ \\
\hline \multicolumn{2}{|c|}{$\begin{array}{l}{ }^{a}: \text { Only aortic abdominal surgery and distal artery bypass were classified as high risk } \\
\text { surgery in our study. All other surgeries were classified as intermediate risk study. } \\
{ }^{b}: \text { Data extracted from the anaesthesiologic consultation }\end{array}$} \\
\hline
\end{tabular}


Table 3: Cost of different cardiac exams in French healthcare system ${ }^{19}$

\begin{tabular}{|l|l|}
\hline 12 lead electrocardiogram & 14,26 euros \\
\hline Resting trans-thoracic echocardiography & 96,49 euros \\
\hline Exercise electrocardiogram & 76,80 euros \\
\hline Stress echocardiography & 161,31 euros \\
\hline Radionuclide myocardial perfusion imaging & 261,91 euros \\
\hline Invasive coronary angiography & 259,20 euros \\
\hline
\end{tabular}




\section{Legends of figures}

\section{Figure 1: Flow chart diagram}

Figure 2: Type of first-line cardiac stress exams ordered by cardiologists

-Results are expressed in percentage of the 60 first-line cardiac stress exams ordered by cardiologists

\section{Figure 3: Appropriateness of cardiac stress test exams ordered by cardiologists}

A cardiac stress exam is of appropriate use if : delaying surgery is possible, the result would change therapeutic strategy, the functional capacity of the patient is less than 4 metabolic equivalent of task and the Revised Cardiac Index Risk (RCRI) score is 2 or more in case of high risk surgery or the RCRI score is 3 or more in case intermediate risk surgery ${ }^{5}$. 
Figure 1

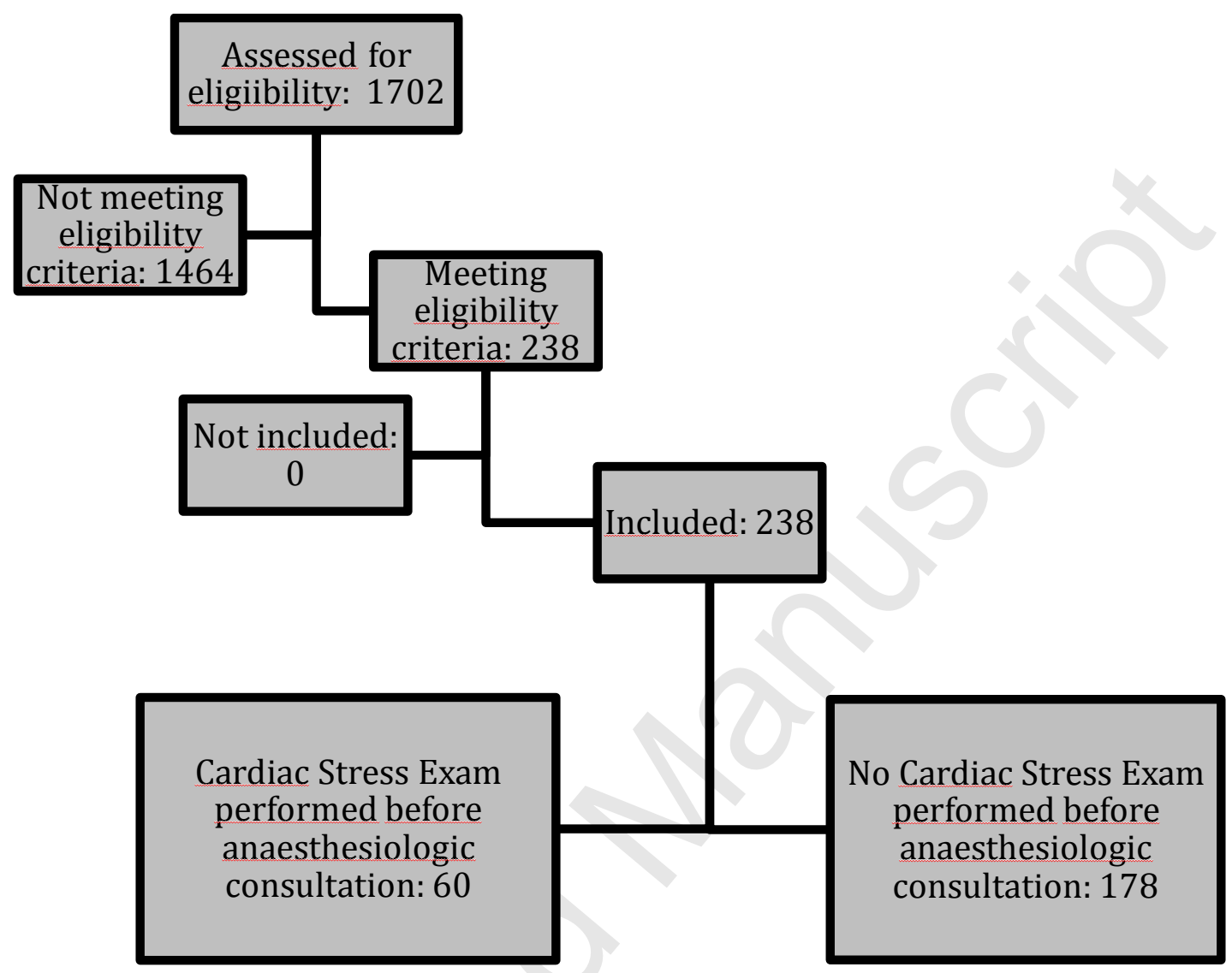




\section{Figure 2}

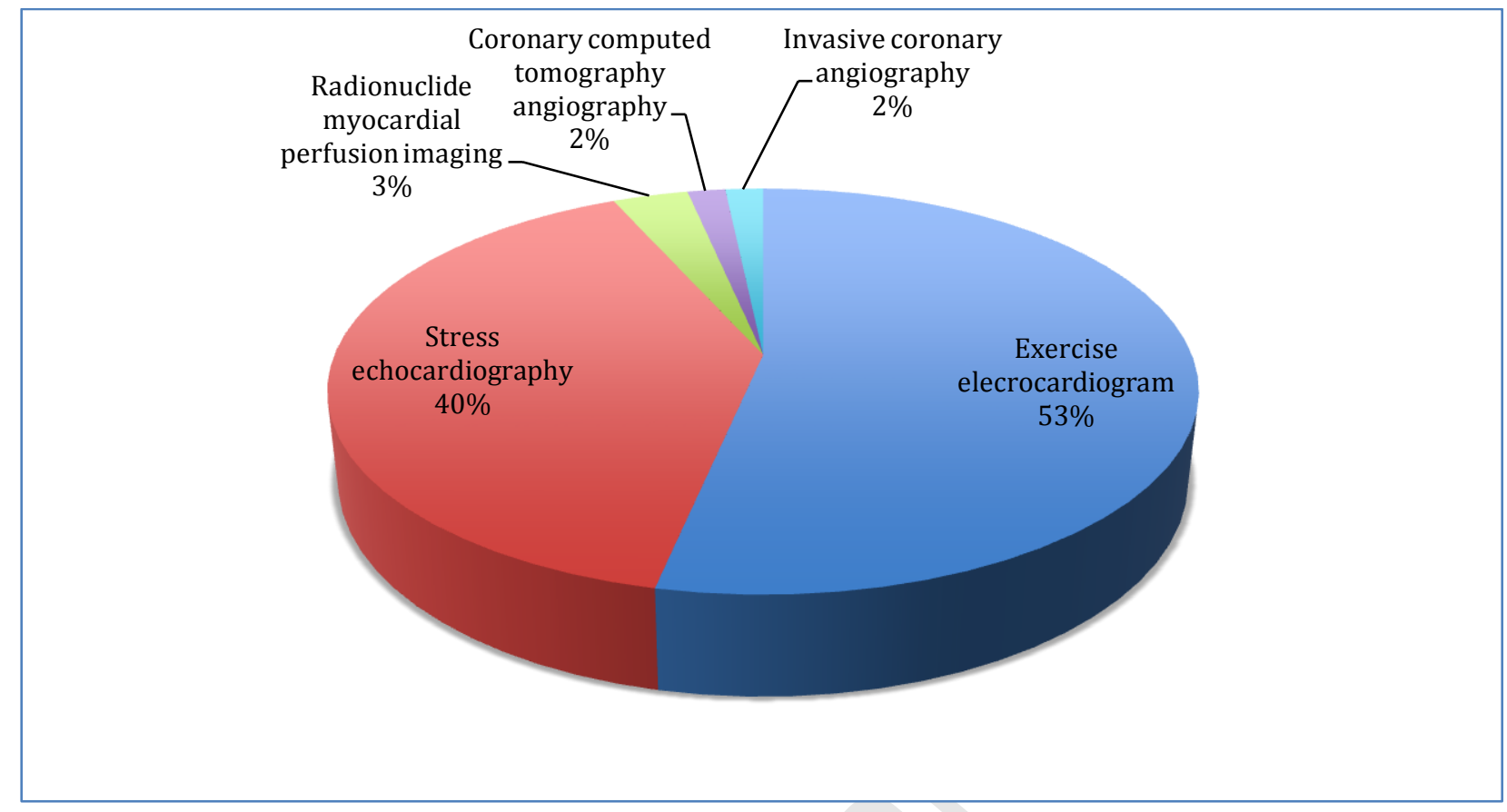




\section{Figure 3}

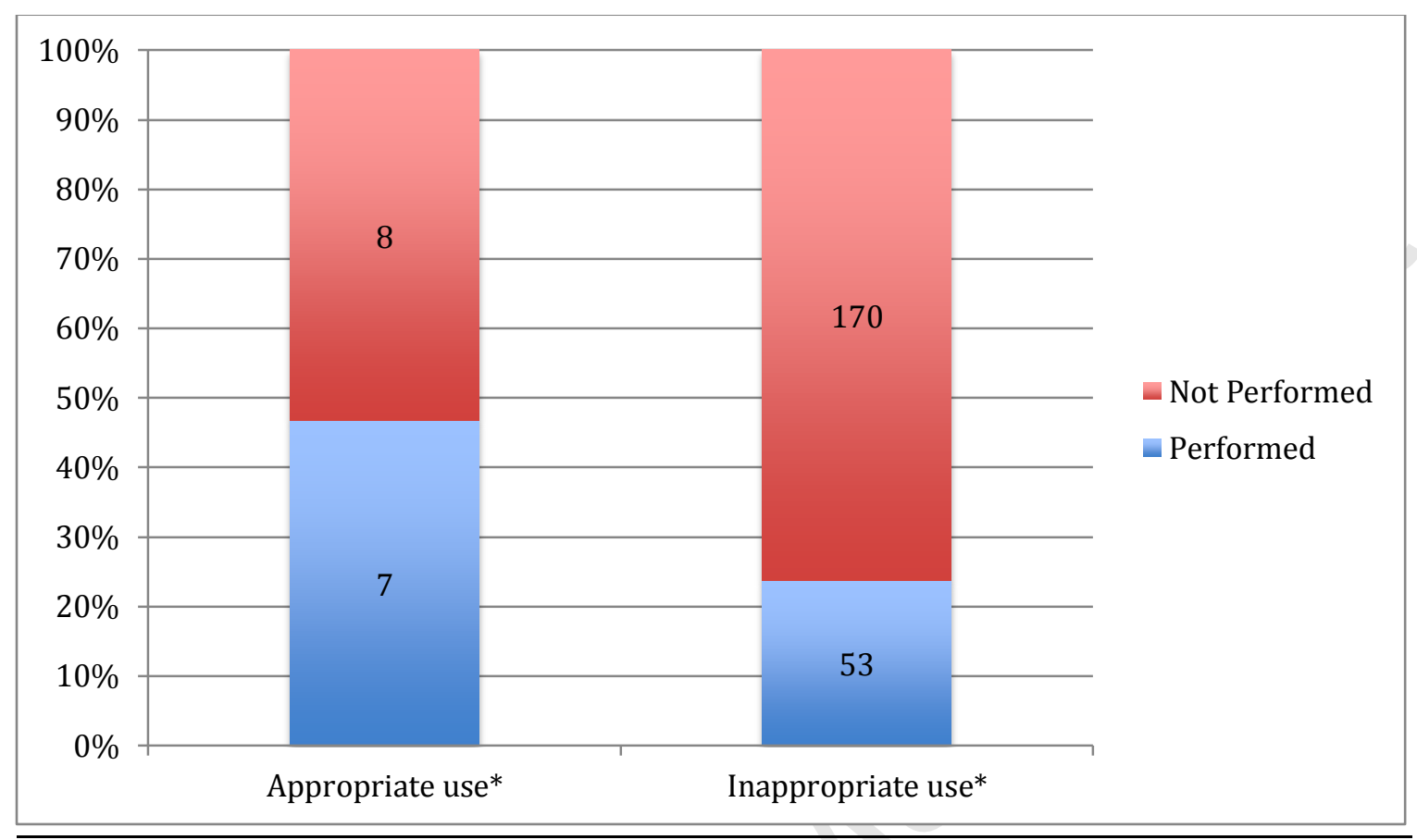

